\title{
Low Density Lipoprotein
}

\section{A METABOLIC PATHWAY FOR RETURN OF CHOLESTEROL TO THE SPLANCHNIC BED}

\author{
A. Sniderman, D. Thomas, D. Marpole, and B. Teng, The Cardiovascular Research \\ Unit, Royal Victoria Hospital, Department of Cardiology, Montreal, Quebec \\ H3A 1Al Canada
}

\begin{abstract}
A B S T RACT The mechanism(s) by which cholesterol returns to the splanchnic bed from peripheral tissues are not well understood. To study this phenomenon in fasting man, lipoproteins were isolated from plasma obtained from hepatic vein and aorta. Cholesterol content of each lipoprotein class was determined and arteriovenous (AV) differences could be calculated for each patient. The results in the first 24 patients indicated splanchnic secretion of very low density lipoprotein cholesterol (mean $\mathrm{AV}$ difference $-3 \mathrm{mg} / 100 \mathrm{ml}, P<0.01$ ), but not significant AV difference for total cholesterol, high density lipoprotein cholesterol, or low density lipoprotein (LDL) B protein. In contrast, for LDL $(d 1.006-1.063 \mathrm{~g} / \mathrm{ml})$, there was significant uptake of cholesterol across the AV bed $+8 \mathrm{mg} / 100 \mathrm{ml}, P<0.0002)$. In a further 15 patients, similar samples were obtained and intermediate density lipoprotein isolated at $d 1.006-1.019 \mathrm{~g} / \mathrm{ml}$ and LDL at $1.019-1.063 \mathrm{~g} / \mathrm{ml}$. The AV difference previously noted could now be localized to the 1.019-1.063 cholesterol ester moiety $(+8 \mathrm{mg} / 100 \mathrm{ml}, P<0.0005)$. In the final 14 patients, the LDL cholesterol AV difference was again confirmed and shown to be unrelated to heparin. As well, there was secretion of triglyceride in the hepatic vein LDL. These quantitative data obtained in man raise the possibility that LDL rather than high density lipoprotein transports cholesterol ester to the splanchnic bed.
\end{abstract}

\section{INTRODUCTION}

Like other lipids that are nonwater-soluble, plasma cholesterol is present in lipoproteins. Most cholesterol enters plasma in chylomicrons, very low density lipoprotein (VLDL), and high density lipoprotein

\footnotetext{
Received for publication 31 December 1976 and in revised form 5 November 1977 .
}

(HDL) ${ }^{1}$ - three classes of lipoproteins secreted by the liver and small intestines (1). In man, the major portion of plasma cholesterol, however, is not present in these lipoproteins, but rather in low density lipoprotein (LDL) - a breakdown product of VLDL (2). Earlier data suggested that the liver was the exclusive catabolic site of the LDL macromolecule (3). But this concept was challenged both by the observation that hepatectomy in swine and dogs did not arrest the irreversible clearance of LDL $B$ protein from plasma (4) and the demonstration by Brown and Goldstein (5) that LDL B protein may bind to and be degraded by mesenchymal tissues such as skin fibroblasts, arterial smooth muscle cells, and lymphocytes. This sequence results in internalization of the cholesterol moiety of the LDL which in turn regulates cellular cholesterol synthesis. As a consequence, as much as $2 \mathrm{~g}$ of cholesterol may be deposited each day in mesenchymal tissues as a result of the peripheral degradation of LDL (6). In addition, all body tissues can synthesize cholesterol. Because cellular cholesterol content remains constant, synthesized and deposited cholesterol must be returned to the liver which is the only tissue with a significant capacity to catabolize this sterol.

Glomset (7) has suggested that HDL is the lipoprotein that accumulates cholesterol from peripheral tissues for transport to the liver. To our knowledge, however, there is no direct evidence that cholesterol is indeed returned in this form. The present study examined whether in man there was uptake of cholesterol from lipoproteins across the splanchnic bed. The data obtained support the concept that LDL may be

\footnotetext{
${ }^{1}$ Abbreviations used in this paper: AV, arteriovenous; HDL, high density lipoprotein; IDL, intermediate density lipoprotein; LDL, low density lipoprotein; VLDL, very low density lipoprotein.
} 
involved in cholesterol transport from peripheral tissues to liver as well as from liver to peripheral tissues.

\section{METHODS}

LDL composition was determined in samples obtained from aorta and hepatic vein in 53 patients undergoing diagnostic cardiac catheterization for either valvular or ischemic heart diseảse. There were 36 males (mean age $52 \mathrm{yr}$ ) and 17 females (mean age $56 \mathrm{yr}$ ).

Catheterization procedure. Paired samples, in random order in each patient, were collected from the aorta (via a multiple hole catheter inserted in the femoral artery) and the hepatic vein (a ro. 7 endhole catheter inserted in the antecubital vein and advanced to the hepatic vein). All patients had been fasting for at least $8 \mathrm{~h}$ and had received $10 \mathrm{mg}$ of diazepam as premedication. Blood was collected as duplicate samples in tubes containing $1 \mathrm{mg}$ EDTA $/ \mathrm{ml}$.

Chemical analysis. Duplicates of all samples were processed independently, and all subsequent chemical analyses were done in triplicate on each of the duplicate samples.

Plasma was sepárated by centrifugation at $2,500 \mathrm{~g}$ at $4^{\circ} \mathrm{C}$. Lipoproteins were then isolated by ultracentrifugation as described by Havel et al. (8). A 50 Ti rotor was used in a Beckman L2-65B ultracentrifuge (Beckman Instruments, Inc., Spinco Div., Palo Alto, Calif.): The initial sample was ultracehtrifuged for $18 \mathrm{~h}$ at $105,000 \mathrm{~g}$. The supernate, VLDL, $d 1.006 \mathrm{~g} / \mathrm{ml}$ was removed by Pasteur pipette. The density of the infranate was adjusted by addition of $\mathrm{NaCl}$ $\mathrm{KBr}$, and the ultracentrifugation repeated. In the first group of patients, LDL was isolated at $d 1: 006-1.063 \mathrm{~g} / \mathrm{ml}$. In subsequent experiments, intermediate density lipoprotein (IDL) was defined as the $d 1.006-1.019 \mathrm{~g} / \mathrm{ml}$ supernate, whereas LDL was the $1.019-1.063 \mathrm{~g} / \mathrm{ml}$ supernate.

LDL $\mathrm{B}$ protein was determined by radial immunodiffusion in plasma as previously reported (9). With this technique, only the B protein in LDL is measured even though VLDL is present in the plasma sample. The measurement of B protein was repeated in the $\mathrm{LDL}$ isolated by ultracentrifugation, and LDL recovery was calculated in terms of the $B$ protein moiety as shown below.

\%LDL recovery $=(\mathrm{B}$ protein $\mathrm{mg}$ in LDL supernate $) /$

(LDL B protein $\mathrm{mg}$ in plasma sample) $\times 100$.

In each sample, the recovery of LDL was at least $94 \%$, and in the total series, the mean recovery of LDL from the hepatic vein and aorta did not differ significantly, being 97.5 and $96.8 \%$, respectively.

Cholesterol was determined according to Abell et al. (10) with the color reagent of Zak et al. (11). Free and ester cholesterol were measured after digitonin precipitation (12); triglyceride was determined by the method of Carlson (13). The reported values each represent the mean of six measurements: The coefficient of variation for cholesterol and B protein (either in plasma or in individual lipoproteins) was $<3 \%$ whereas for triglycerides, it was $<5 \%$.

HDL cholesterol was calculated as follows: HDL cholesterol $=$ plasma cholestérol $-(\mathrm{VLDL}+\mathrm{IDL}+\mathrm{LDL}$ cholesterol).

Statistical analyses. All samples were handled identically, and all arteriovenous (AV) differences between artery and hepatic vein lipoproteins for each grouping of data were first subjected to a Kolmogorov-Smirnov test (14) to determine whether the data were normally distributed. Only if this condition were met was the possible significance of the arterial-hepatic vein difference determined by paired Student's $t$ test.

\section{RESULTS}

In the first group of 24 patients, the AV difference was determined for total cholesterol and VLDL, LDL, and HDL cholesterol. At the same time, LDL B protein was determined. The individual data for each patient are given in Table I; the mean AV differences are shown in Fig. 1. For total plasma cholesterol, the mean AV difference was $+2 \pm 1.3 \mathrm{mg} / 100 \mathrm{ml}$ (mean \pm SEM). This value is not statistically significant. The mean AV difference for LDL $d$ 1.006-1.063 $\mathrm{g} / \mathrm{ml}$ was $+8 \pm 1.9 \mathrm{mg} / \mathrm{ml}$. This difference was highly significant $(P<0.0002)$ and suggested net uptake of cholesterol across the splanchnic bed. In contrast, the mean AV difference for LDL B protein (not shown in Fig. 1) was $-1 \pm 0.7 \mathrm{mg} / 100 \mathrm{ml}$ and was not significant. The mean AV differences for VLDL and HDL cholesterol were negative $(-3 \pm 1.1$ and $-3 \pm 1.4 \mathrm{mg} / 100 \mathrm{ml}$, respectively) indicting splanchnic production of these lipoproteins. Only the mean AV difference for VLDL cholesterol, however, was statistically significant $(P<0.01)$.

These findings pointed to a selective decrease in the cholesterol moiety in hepatic vein LDL occurring without any change in the protein portion. The patients in group 2 were studied to determine whether this difference could be assigned to either the IDL $d$ $1.006-1.019 \mathrm{~g} / \mathrm{ml}$ or the LDL $d 1.019-1.063 \mathrm{~g} / \mathrm{ml}$ fraction. Also, the LDL cholesterol was divided into free and ester fractions to determine whether the splanchnic uptake could be localized to one lipid type. The mean AV difference found in these patients are shown in Fig. 2 with the individual values from which these are derived given in Table II.

For IDL-the $d 1.006-1.019 \mathrm{mg} / \mathrm{ml}$ fraction-the average arterial and hepatic vein cholesterol were almost identical (10.5 and $10.2 \mathrm{mg} / 100 \mathrm{ml}$, respectively) and the AV difference $+0.3 \mathrm{mg} / 100 \mathrm{ml}$ was not significant.

For LDL, as in group 1, there was no significant difference between arterial and hepatic vein B protein. But again, as in group 1 , the total LDL cholesterol was significantly higher in the arterial sample than in the venous. This difference was not the result of a decrease in the hepatic vein LDL free cholesterol (mean AV difference $+0.3 \pm 1.3 \mathrm{mg} / 100 \mathrm{ml}, P$, not significant), but was located in the LDL cholesterol ester fraction $(+8 \pm 1.9 \mathrm{mg} / 100 \mathrm{ml}, P<0.0005)$. The failure to find a similar AV difference for IDL cholesterol, LDL free cholesterol, or LDL B protein excludes any systematic sampling error that might produce selective hemodilution of the venous sample.

In patients in group 3, two questions were examined. 
TABLE I

Lipoprotein Cholesterol from Hepatic Vein and Aorta in Group 1

\begin{tabular}{|c|c|c|c|c|c|c|c|c|c|c|}
\hline \multirow[b]{2}{*}{ Patient } & \multicolumn{2}{|c|}{ Total plasma $\mathrm{C}^{*}$} & \multicolumn{2}{|c|}{$\begin{array}{c}\text { VLDL C } \\
(d \quad 1.006 \mathrm{~g} / \mathrm{ml})\end{array}$} & \multicolumn{2}{|c|}{$\begin{array}{c}\text { LDL C } \\
(d 1.006-1.063 \\
\mathrm{g} / \mathrm{ml})\end{array}$} & \multicolumn{2}{|c|}{ B (protein LDL) } & \multicolumn{2}{|c|}{$\begin{array}{c}\text { HDL C } \\
(d 1.063 \mathrm{~g} / \mathrm{ml})\end{array}$} \\
\hline & At & HV\$ & $\mathbf{A}$ & HV & $\mathbf{A}$ & $\mathrm{HV}$ & $\mathbf{A}$ & HV & $\mathbf{A}$ & HV \\
\hline & \multicolumn{2}{|c|}{$m g / 100 m l$} & \multicolumn{2}{|c|}{$m g / 100 \mathrm{ml}$} & \multicolumn{2}{|c|}{$m g / 100 \mathrm{ml}$} & \multicolumn{2}{|c|}{$m g / 100 \mathrm{ml}$} & \multicolumn{2}{|c|}{$m g / 100 \mathrm{ml}$} \\
\hline 1 & 246 & 242 & 24 & 28 & 196 & 192 & 99 & 96 & 26 & 22 \\
\hline 2 & 216 & 218 & 21 & 27 & 174 & 158 & 88 & 89 & 21 & 33 \\
\hline 3 & 212 & 218 & 14 & 14 & 163 & 152 & 68 & 73 & 35 & 52 \\
\hline 4 & 156 & 148 & 7 & 7 & 108 & 100 & 52 & 55 & 41 & 41 \\
\hline 5 & 184 & 188 & 7 & 7 & 131 & 123 & 60 & 68 & 46 & 58 \\
\hline 6 & 222 & 222 & 39 & 39 & 162 & 166 & 95 & 96 & 21 & 17 \\
\hline 7 & 190 & 192 & 26 & 31 & 133 & 143 & 94 & 101 & 31 & 18 \\
\hline 8 & 196 & 198 & 39 & 39 & 125 & 117 & 95 & 95 & 32 & 42 \\
\hline 9 & 260 & 260 & 40 & 50 & 194 & 173 & 130 & 129 & 26 & 37 \\
\hline 10 & 202 & 192 & 17 & 17 & 134 & 120 & 90 & 90 & 51 & 55 \\
\hline 11 & 226 & 226 & 22 & 21 & 161 & 156 & 129 & 131 & 43 & 49 \\
\hline 12 & 273 & 256 & 44 & 57 & 160 & 137 & 154 & 151 & 69 & 62 \\
\hline 13 & 170 & 169 & 16 & 10 & 138 & 136 & 82 & 83 & 16 & 23 \\
\hline 14 & 210 & 208 & 24 & 42 & 156 & 135 & 95 & 96 & 30 & 31 \\
\hline 15 & 186 & 184 & 18 & 20 & 133 & 130 & 91 & 91 & 35 & 34 \\
\hline 16 & 190 & 186 & 20 & 24 & 136 & 130 & 93 & 94 & 34 & 32 \\
\hline 17 & 200 & 180 & 10 & 19 & 150 & 126 & 140 & 135 & 40 & 35 \\
\hline 18 & 166 & 164 & 41 & 42 & 90 & 90 & 95 & 93 & 35 & 32 \\
\hline 19 & 192 & 184 & 22 & 20 & 113 & 108 & 95 & 98 & 57 & 56 \\
\hline 20 & 164 & 164 & 40 & 40 & 88 & 82 & 96 & $95^{3}$ & 36 & 42 \\
\hline 21 & 224 & 220 & 40 & 40 & 180 & 166 & 134 & 137 & 4 & 14 \\
\hline 22 & 178 & 180 & 12 & 16 & 105 & 91 & 69 & 69 & 61 & 73 \\
\hline 23 & 140 & 144 & 8 & 8 & 108 & 112 & 81 & 88 & 24 & 24 \\
\hline 24 & 178 & 184 & 36 & 42 & 108 & 110 & 104 & 104 & 34 & 32 \\
\hline
\end{tabular}

* Cholesterol.

$\$$ Aortic.

$\$$ Hepatic vein.

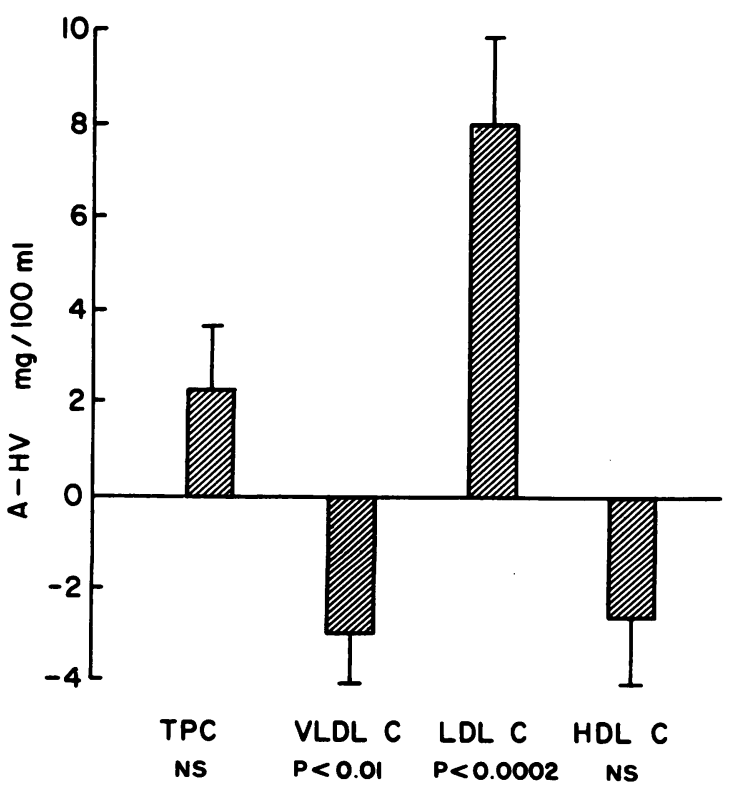

First, samples from patients in the first two groups had been obtained after heparin administration, a drug routinely given intravenously during cardiac catheterization to prevent thromboembolic complications. Therefore, the changes observed previously could have been a consequence of heparin. Thus, a sample was collected from the hepatic vein and femoral artery before any heparin was given, and similar șamples were obtained $10 \mathrm{~min}$ after $10,000 \mathrm{U}$ of sodium heparin. Because cholesterol ester and triglyceride, the two nonpolar lipids, are likely found within the LDL core, we also examined whether, if the hepatic vein cholesterol ester were reduced, there was a con-

FIgURE 1 Paired samples analysis of the AV difference for total plasma cholesterol (TPC), total cholesterol (C), VLDL cholesterol, LDL cholesterol (d 1.006-1.063 g/ml), and HDL cholesterol is shown for the 24 patients in group 1 . For VLDL cholesterol, the difference is significant and negative, indicating splanchnic secretion. The converse is true for $\mathrm{LDL}$ cholesterol. A-HV, aortic-hepatic vein. 


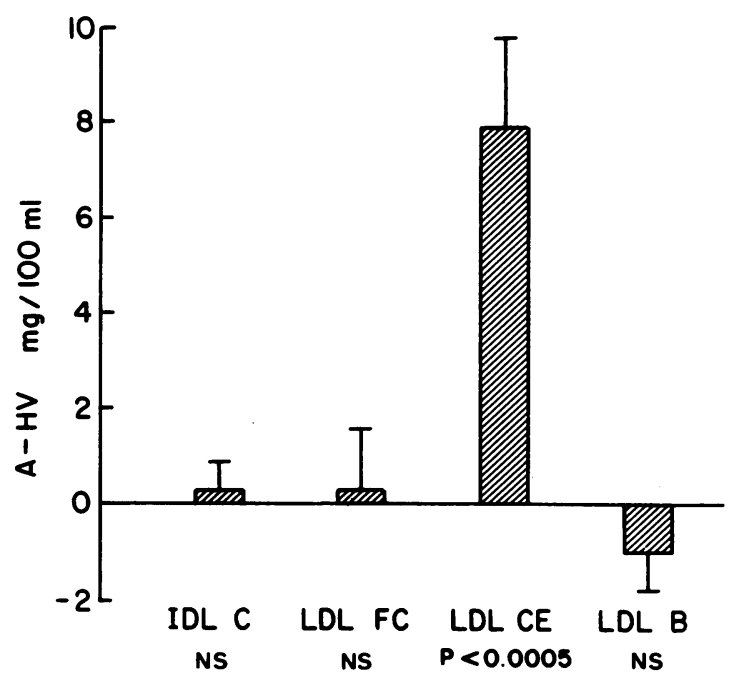

FIgure 2 The AV difference for cholesterol (C) in IDL and LDL is shown for the 15 patients in group 2. Only for LDL cholesterol ester (CE) is the difference significant. A-HV, aortic-hepatic vein; FC, free cholesterol.

comitant reciprocal increase in LDL triglyceride. The results in 14 patients are shown in Fig. 3. Again, there was no significant $\mathrm{AV}$ difference for total plasma cholesterol or LDL B protein either before or after heparin administration. The mean AV difference for LDL cholesterol was $+12 \mathrm{mg} / 100 \mathrm{ml}$ before heparin and $+14 \mathrm{mg} / 100 \mathrm{ml} 10 \mathrm{~min}$ after heparin. Although both are significant $(P<0.005)$, the splanchnic uptake

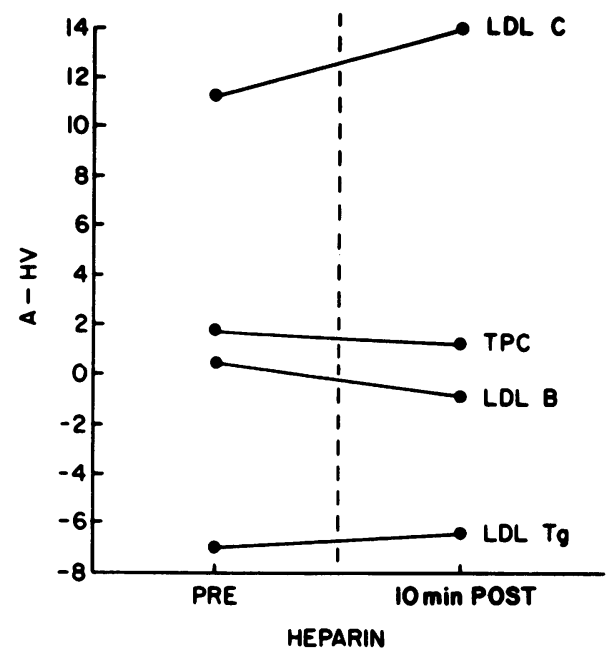

Figure 3 The mean AV difference for total cholesterol (C), total plasma cholesterol (TPC), LDL cholesterol, LDL triglyceride (LDL Tg), and LDL B protein is shown before and after heparin. For total cholesterol and LDL B protein, the AV difference is not significant. For LDL cholesterol, it is significant and positive (indicating splanchnic uptake), whereas the LDL triglyceride, it is significant and negative (indicating splanchnic secretion). A-HV, aortic-hepatic vein.

of LDL cholesterol ( $d 1.019-1.063 \mathrm{~g} / \mathrm{ml})$ is present before heparin was given and its magnitude is not altered after heparin. It is of interest that hepatic vein LDL contained more triglyceride than aortic LDL, both before and after heparin. The mean AV difference

TABLE II

Cholesterol in d 1.006-1.019 and 1.019-1.063 g/ml from Aorta and Hepatic Vein in Group 2

\begin{tabular}{|c|c|c|c|c|c|c|c|c|c|c|}
\hline \multirow[b]{2}{*}{ Patient } & \multicolumn{2}{|c|}{$\begin{array}{c}\text { IDL TC* } \\
d \begin{array}{c}1.006-1.019 \\
\mathrm{~g} / \mathrm{ml}\end{array}\end{array}$} & \multicolumn{2}{|c|}{$\begin{array}{c}\text { LDL TC } \\
d 1.019-1.063 \\
\mathrm{~g} / \mathrm{ml}\end{array}$} & \multicolumn{2}{|c|}{$\begin{array}{c}\text { LDL FC } \downarrow \\
d 1.019-1.063 \\
\mathrm{~g} / \mathrm{ml}\end{array}$} & \multicolumn{2}{|c|}{$\begin{array}{c}\text { LDL CE } \S \\
d 1.019-1.063 \\
\mathrm{~g} / \mathrm{ml}\end{array}$} & \multicolumn{2}{|c|}{ LDL B protein } \\
\hline & $\mathbf{A}$ & HV & A & HV & $\mathbf{A}$ & HV & A & HV & A & HV \\
\hline & \multicolumn{2}{|c|}{$m g / 100 \mathrm{ml}$} & \multicolumn{2}{|c|}{$m g / 100 m l$} & \multicolumn{2}{|c|}{$m g / 100 \mathrm{ml}$} & \multicolumn{2}{|c|}{$m g / 100 \mathrm{ml}$} & \multicolumn{2}{|c|}{$m g / 100 m l$} \\
\hline 1 & 11 & 11 & 156 & 157 & 38 & 38 & 118 & 119 & 129 & 131 \\
\hline 2 & 8 & 8 & 140 & 121 & 43 & 40 & 98 & 81 & 97 & 98 \\
\hline 3 & 18 & 14 & 199 & 182 & 43 & 43 & 156 & 140 & 154 & 151 \\
\hline 4 & 11 & 14 & 144 & 138 & 38 & 42 & 106 & 96 & 82 & 83 \\
\hline 5 & 14 & 12 & 156 & 133 & 47 & 40 & 109 & 92 & 95 & 96 \\
\hline 6 & 18 & 12 & 133 & 130 & 39 & 41 & 94 & 89 & 91 & 91 \\
\hline 7 & 16 & 18 & 140 & 131 & 35 & 39 & 104 & 92 & 93 & 94 \\
\hline 8 & 3 & 4 & 90 & 90 & 21 & 22 & 69 & 68 & 95 & 93 \\
\hline 9 & 9 & 8 & 109 & 104 & 27 & 29 & 82 & 74 & 95 & 98 \\
\hline 10 & 8 & 9 & 180 & 164 & 56 & 43 & 124 & 121 & 134 & 137 \\
\hline 11 & 5 & 5 & 108 & 98 & 26 & 26 & 82 & 72 & 69 & 69 \\
\hline 12 & 8 & 8 & 108 & 108 & 26 & 28 & 82 & 80 & 104 & 104 \\
\hline 13 & 7 & 8 & 108 & 117 & 26 & 33 & 82 & 84 & 81 & 88 \\
\hline 14 & 9 & 10 & 104 & 104 & 26 & 26 & 78 & 78 & 64 & 70 \\
\hline 15 & 12 & 12 & 150 & 126 & 44 & 41 & 106 & 85 & 140 & 135 \\
\hline
\end{tabular}

* Total cholesterol.

\$ Free cholesterol.

$\S$ Cholesterol ester. 


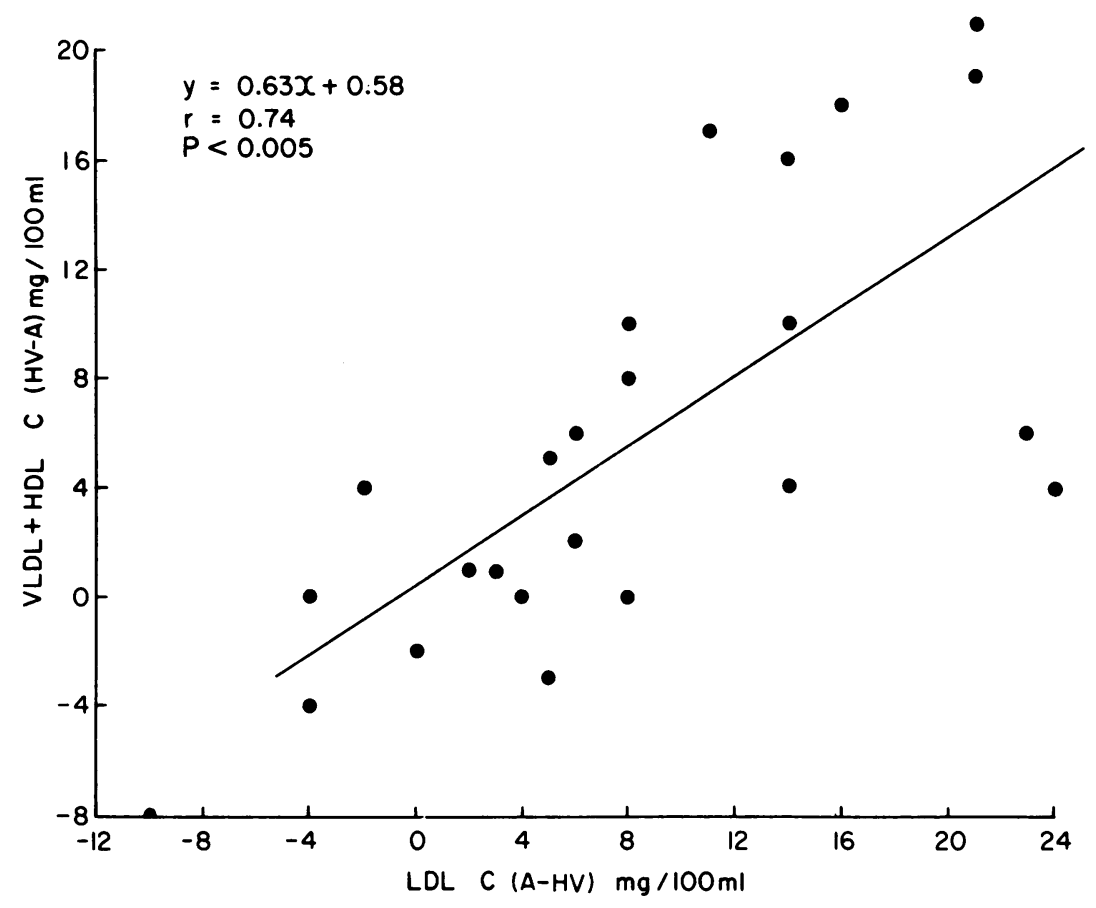

FIGURE 4 The LDL cholesterol (C) AV difference for each patient in group 1 is plotted on the abscissa, the corresponding net VA (i.e. hepatic vein-aorta) difference for VLDL plus HDL cholesterol is shown on the ordinate. A significant linear relation between these is shown above. A-HV, aortic-hepatic vein.

was negative $7.8 \pm 2.2 \mathrm{mg} / 100 \mathrm{ml}$, indicating splanchnic output of triglyceride in density range, $d$ 1.019-1.063 $\mathrm{g} / \mathrm{ml}$ and significant $(P<0.025)$.

Finally, we examined the results in group 1 patients to determine whether there was a linear relation between splanchnic uptake of LDL cholesterol and splanchnic secretion of cholesterol in VLDL and HDL. The results are shown in Fig. 4. There is a highly significant $(P<0.005)$ relation with a correlation coefficient of 0.74 between LDL cholesterol uptake and cholesterol secretion in the two other lipoprotein fractions.

\section{DISCUSSION}

These data lead to two principle conclusions. First, there is no significant AV difference across the splanchnic bed for HDL and, thus, no direct evidence to indicate that in humans HDL transports cholesterol to the splanchnic bed. Second, LDL, in contrast to HDL, leaves the splanchnic bed containing less cholesterol ester but more triglyceride for the same amount of $B$ protein. These results suggest that human LDL does transport cholesterol to the splanchnic bed. Further, the evidence indicates that it is the cholesterol ester rather than the free cholesterol fraction that is taken up by the splanchnic bed.

It is clear that there are major interspecies dif- ferences in lipoprotein metabolism. Therefore, conclusions from our findings should be restricted principally to the human situation. Nevertheless, our results are in a general sense consistent with previous concepts of LDL metabolism, in both swine and man - two species with similar LDL metabolism. In man, the plasma decay curve of ${ }^{125}$ I-LDL is biexponential, indicating that plasma LDL exists in a rapid reversible equilibrium with a large extravascular pool (15). The plasma decay curve of ${ }^{125}$ I-LDL in swine shares these same features. In the latter species, we have directly shown that the major portion of this extravascular pool can be anatomically assigned to the liver (16). As well, additional experiments in hepatectomized dogs and swine indicated that the liver was unlikely to be a major site of catabolism of the B protein moiety of LDL (4). These findings are consistent with the work of Brown and Goldstein (5), which shows that human mesenchymal cells may bind and degrade B proteins. Their model, although it explains the intracellular regulation of cholesterol synthesis, does not indicate the pathway by which cholesterol is returned to the splanchnic bed for catabolism. It is important to note that even though the hepatectomy experiments excluded the liver as a necessary site for $B$ protein catabolism, they did not exclude a role for LDL as a carrier of cholesterol to the liver for its catabolism. Indeed, the plasma half-life of LDL posthepatectomy 
was markedly diminished, and there was suggestive evidence that this was accompanied by a change in LDL composition. Specifically, there appeared to be more cholesterol and less triglyceride in the LDL particle in the posthepatectomy state (6). Thus, because cholesterol can only be degraded in the liver even though the irreversible removal of LDL from plasma occurs in peripheral tissues, we suggest that cholesterol ester is returned to the splanchnic bed and then removed from LDL while the latter is in an extravascular hepatic space.

The absolute AV differences noted in this study are small. Because this was anticipated, the study was designed to permit the use of the paired sample method. Because this method allows intrapatient analysis, it thus eliminates the large interpatient difference in lipoprotein cholesterol levels.

However, if the observed AV differences in this study are of statistical significance, do they point to events of physiologic importance? It must be remembered that the differences observed were derived from simultaneously drawn samples. Therefore, the absolute flux is a function of the AV differences and splanchnic blood flow. The $95 \%$ confidence limits for the AV LDL cholesterol ester difference of $8 \mathrm{mg} / 100 \mathrm{ml}$ are $3.5-12.5$ $\mathrm{mg} / 100 \mathrm{ml}$. Even though splanchnic flow was not measured in the present study, an assumed value of 1 liter/ min would yield a minimum estimate of LDL cholesterol ester turnover of $1 \mathrm{~g} / \mathrm{h}$. This, of course, far exceeds the previous estimates of LDL cholesterol ester turnover of $4 \mathrm{~g} /$ day derived from radioisotopic studies (17). At a minimum, however, the present study supports a principle conclusion of the radioisotope method, in that both derive a turnover of LDL cholesterol ester far in excess of LDL B protein. Both types of study indicate that the metabolic fate of the core lipid differs from the surface protein and, thus, that the components of LDL undergo separate metabolic fates at different rates. Nevertheless, although the conclusion remains the same qualitatively, the quantitative discrepancies must be explained. First, the present study was conducted with restricted sampling time under specific circumstances. The patients were not in metabolic steady state, but were fasting and likely frightened; both conditions would favor VLDL synthesis. In addition, VLDL production is not constant but phasic. Depending on study conditions, over a 24 -h period from 4 to $20 \mathrm{~g}$ cholesterol may be required just for splanchnic VLDL synthesis (18-20). The rate of cholesterol incorporation into VLDL at any time would vary depending on the rate of VLDL synthesis. Second, the radioisotopic studies produce a minimum estimate of cholesterol ester turnover in LDL if the cholesterol removed were to be reused in VLDL synthesis. This occurs because the labeled molecule would soon return to LDL as VLDL is catabolized. The present study suggests that the majority of choles- terol ester removed from LDL is reused in VLDL and HDL synthesis. No significant AV difference was observed for plasma total cholesterol and none would be expected because only 1-2 g cholesterol are catabolized to bile acid over $24 \mathrm{~h}$ (17). Not only in the general sense do the results of the present study support the concept that cholesterol is reused in splanchnic lipoprotein production, but it is important to note that the size of the cholesterol AV gradient was directly related to simultaneous production of HDL and VLDL. This observation agrees with previous work by others showing that the rate of LDL cholesterol turnover is directed to VLDL triglyceride production (21). It is of some interest, however, that net LDL cholesterol ester uptake across the splanchnic bed exceeds that of VLDL and HDL output, suggesting that this pathway may supply cholesterol for catabolism.

Finally, the changes observed in LDL composition should be explained. The present study indicates that not only was there a decrease in LDL cholesterol ester, but there was an apparent reciprocal increase in LDL triglyceride. Compared to VLDL, relatively little attention has been paid to possible compositional changes in LDL. However, Lees noted (22) that the LDL cholesterol to $\mathrm{B}$ protein ratio was lower in type IV hyperlipidemia than normal. Carlson (23) has suggested that in certain hyperlipidemic states, there is an inverse relationship between LDL cholesterol and triglyceride, an observation supported by the work of Myers et al. (24). As well, in a recent study of changes in LDL composition after myocardial infarction, it was shown that the cholesterol ester and triglyceride fractions of LDL varied reciprocally and changed predictably with differences in absolute concentration (25). All these observations are consistent with a pseudomicellar model of LDL in which the surface components-B protein, free cholesterol, and phospholipids - are present in fixed amounts, but the interior shell of cholesterol ester and triglyceride are present in an inverse relation. It is generally conceived that cholesterol ester and triglyceride are the least exchangeable of the major lipid classes in the lipoprotein fractions. Nichols and Smith (26) have indicated that cholesterol ester may transfer from HDL to VLDL in exchange for triglyceride. This model, however, does not agree with the results of Zilversmit et al. (27), who have shown that rapid cholesterol ester exchange can occur between LDL and VLDL in hyperlipidemic rabbits. The discrepancy is of some importance in the interpretation of our results. If the original studies are correct, it is conceivable that our findings could reflect cholesterol ester transfer from LDL to VLDL in exchange for triglyceride. However, recent work in our laboratory using human lipoproteins ${ }^{2}$ supports the concept that

\footnotetext{
${ }^{2}$ Unpublished observations.
} 
cholesterol ester can exchange rapidly, but no net transfer occurs between lipoproteins.

Thus, the following mechanism for cholesterol transport in plasma might be contemplated. HDL are thought to accumulate cholesterol from peripheral tissues. The cholesterol ester formed in HDL may be transferred either to VLDL in exchange for triglyceride or, in part, directly to LDL. In either case, with VLDL breakdown, the cholesterol ester would arrive at LDL. Alternatively, VLDL may be the exclusive source of LDL cholesterol. Cholesterol ester is removed from LDL in the splanchnic bed and LDL particle stability maintained by addition of triglyceride. This likely occurs while LDL is present in an extravascular hepatic bed. However, because in the present study portal vein blood was not sampled, the phenomenon we observed can be localized only to the splanchnic bed, and the relative influence of the liver vs. the intestine in this process cannot be assessed. Finally, the cholesterol derived from LDL is reused in the synthesis of VLDL and HDL. This scheme would describe the possibilities of cholesterol transport to the splanchnic bed. It seems clear from the studies of Brown and Goldstein (5) that LDL is also the major vehicle for transport of cholesterol to peripheral tissues.

\section{ACKNOWLEDGMENTS}

The authors wish to thank Mr. Ernest Yu for technical assistance. We are also grateful to Dr. M. McGregor and Dr. D. Steinberg for their encouragement and support.

This study was supported by funds from the Joseph Edwards Foundation and the Medical Research Council of Canada.

\section{REFERENCES}

1. Eisenberg, S., and R. I. Levy. 1975. Lipoprotein metabolism. Adv. Lipid Res. 13: 1-89.

2. Stone, N. J., and R. I. Levy. 1972. Hyperlipoproteinemia and coronary heart disease. Prog. Cardiovasc. Dis. 14: 341-359.

3. Hay, R. V., L. A. Pottenger, A. L. Reingold, G. S. Getz, and R. W. Wissler. 1971. Degradation of ${ }^{125}$ I-labelled serum low density lipoprotein in normal and estrogentreated male rats. Biochem. Biophys. Res. Commun. 44: 1471-1477.

4. Sniderman, A. D., T. E. Carew, J. G. Chandler, and D. Steinberg. 1974. Paradoxical increase in rate of catabolism of low density lipoproteins after hepatectomy. Science (Wash. D. C.). 183: 526-528.

5. Brown, M. S., and J. L. Goldstein. 1976. Familial hypercholesterolemia: a genetic defect in the low density lipoprotein receptor. N. Engl. J. Med. 294: 1386-1390.

6. Steinberg, D., T. E. Carew, D. B. Weinstein, and T. Koschinsky. 1975. Binding, Uptake and Catabolism of Low Density (LDL) and High Density (HDL) Lipoproteins by Cultured Smooth Muscle Cells in Lipids, Lipoproteins and Drugs. D. Kritchevsky, R. Paoletti, and W. L. Holmes, editors. Plenum Publishing Corporation, New York. 90-98.

7. Glomset, J. A. 1968. The plasma lecithin: cholesterol acyltransferase reaction. J. Lipid Res. 9: 155-167.
8. Havel, R. J., H. A. Eder, and J. H. Bragdon. 1965. The distribution and chemical composition of ultracentrifugally separated lipoproteins in human serum. J. Clin. Invest. 34: 1345-1353.

9. Sniderman, A. D., B. Teng, and M. Jerry. 1975. Determination of B protein of low density lipoprotein directly in plasma. J. Lipid Res. 16: 465-467.

10. Abell, L. L., B. B. Levy, B. B. Brodie, and F. E. Kendall. 1952. A simplified method for the estimation of total cholesterol in serum and determination of its specificity. J. Biol. Chem. 195: 357-366.'

11. Zak, B., N. Moss, A. J. Boyle, and A. Zlutkis. 1954. Reactions of certain unsaturated steroids with acid iron reagent. Anal. Chem. 26: 767-776.

12. Sperry, W. M., and M. Webb. 1950. A revision of the Schoenheimer-Sperry method for cholesterol determination. J. Biol. Chem. 187: 97-106.

13. Carlson, L. A. 1963. Determination of serum triglycerides. J. Atheroscler. Res. 3: 334-336.

14. Stokul, R. R., and F. J. Rohlf. 1969. Biometry. W. H. Freeman \& Company, San Francisco. 571-575.

15. Langer, T., W. Strober, and R. I. Levy. 1972. The metabolism of lower density lipoprotein in familial type II hyperlipoproteinemia. J. Clin. Invest. 51: 1528-1536.

16. Sniderman, A. D., T. E. Carew, and D. Steinberg. 1975. Turnover and tissue distribution of ${ }^{125}$ I-labelled low density lipoprotein in swine and dogs. J. Lipid Res. 16: $293-299$.

17. Nestel, P. J. 1970. Cholesterol turnover in man. Adv. Lipid Res. 8: 1-39.

18. Havel, R. J., J. P. Kane, E. O. Balasse, N. Seegal, and L. V. Basso. 1970. Splanchnic metabolism of free fatty acids and production of triglycerides of very low density lipoproteins in normotriglyceridemia and hypertriglyceridemia in humans. J. Clin. Invest. 49: 2017-2035.

19. Wolfe, B. M., and S. P. Ahuja. 1977. Effects of intravenously administered fructose and glucose on splanchnic secretion of triglycerides in hypertriglyceridemic men. Metab. Clin. Exp. 26: 963-978.

20. Boberg, J., L. A. Carlson, U. Freyschuss, B. W. Lassers, and M. L. Wahlqvist. 1972. Splanchnic secretion rates of plasma triglycerides and total and splanchnic turnover of plasma free fatty acids in man with normo- and hypertriglyceridemia. Eur. J. Clin. Invest. 2: 454-466.

21. Kudchokar, B. J., and H. S. Sodhi. 1976. Turnover of plasma cholesterol esters and its relationship to other parameters of lipid metabolism in man. Eur. J. Clin. Invest. 6: 285-298.

22. Lees, R. S. 1970. Immunoassay of plasma low density lipoproteins. Science (Wash. D. C.). 169: 493-495.

23. Carlson, L. A. 1976. Lipid composition of the major human serum lipoprotein density classes in different types of hyperlipoproteinemia. Lipoprotein Metabolism. Heiner Greten, editor. Springer-Verlag, Berlin. 69-79.

24. Myers, L. H., N. R. Phillips, and R. J. Havel. 1976. Mathematical evaluation of methods for estimation of the concentration of major lipid components of human serum lipoproteins. J. Lab. Clin. Med. 88: 491-505.

25. Sniderman, A. D., and B. Teng. 1977. Predictable changes in low density lipoprotein composition after acute myocardial infarction. Atherosclerosis. 27: 325-331.

26. Nichols, A. V., and L. Smith. 1965. Effect of very low density lipoproteins on lipid transfer in incubated serum. J. Lipid Res. 6: 206-210.

27. Zilversmit, D. B., L. B. Hughes, and J. Bulmer. 1975. Stimulation of cholesterol ester exchange by lipoproteinfree rabbit plasma. B.B.A. (Biochim. Biophys. Acta) Libr. 409: 393-398. 